\title{
Increased Response of Blood Eosinophils to Various Chemotactic Agents in Quiescent Crohn Disease
}

\author{
M.-A. Denis, R. Louis, M. Malaise, J. Belaiche \& E. Louis \\ Depts. of Gastroenterology, Respiratory Medicine, and Centre d'Etude des Maladies Inflammatoires Chroniques (CEMIC), CHU of Liège, \\ Belgium
}

Background: The number of eosinophils is increased in the mucosae of the digestive and the respiratory tracts in Crohn disease, even clinically quiescent. The mechanisms underlying this panmucosal eosinophilia are unknown. Methods: The response of blood eosinophils to various chemotactic agents was assessed in 15 patients with clinically quiescent Crohn disease. The results were compared with 15 healthy controls. After purification, eosinophils were placed in Boyden microchambers and the chemotactic effect of PAF $\left(10^{-7} \mathrm{M}\right)$, RANTES (50ng/ml), IL-5 (0-20ng/ml), IL-8 (0-50ng/ml), Eotaxin $(0-50 \mathrm{ng} / \mathrm{ml})$ was evaluated. The number of eosinophils in induced sputum of these Crohn disease patients and controls was also assessed and the correlation between chemotaxis and eosinophil count in induced sputum was studied.

Results: PAF and RANTES induced a chemotactic effect both in Crohn disease patients and controls. The chemotactic index was significantly higher in Crohn than controls for PAF $(2.09 \pm 0.24$ versus $1.37 \pm 0.14 ; P<$ 0.05) but not RANTES. With IL-5, IL-8 and Eotaxin, there was no detectable chemotactic effect in controls while in Crohn, we observed a significant dose-dependent chemotactic effect. Furthermore, with Eotaxin 50 $\mathrm{ng} / \mathrm{ml}$, the chemotactic index was significantly higher in Crohn disease patients than controls $(2.42 \pm 0.18$ versus $1.56 \pm 0.28 ; P<0.05)$. A significant increase in sputum eosinophil count and a significant decrease in sputum macrophage count in Crohn disease were observed. However, there was no correlation between eosinophil chemotaxis and sputum eosinophil count in individual patients.

Conclusion: There is an increased response of blood eosinophils to various chemotactic agents, mainly PAF and Eotaxin, in clinically quiescent Crohn disease. This may participate in the mucosal infiltration by eosinophils in this disease.

Key words : Chemotaxis ; Crohn disease ; eosinophils

Crohn disease is characterized by a chronic infiltration of the bowel wall with immune and inflammatory cells (1). Although T lymphocytes and monocytes-macrophages are thought to play a prominent role in the organization of this chronic inflammation (1), the respective roles of the various cell types found in the infiltrate are still not known completely. Emerging evidence suggests that eosinophils may play a greater role than previously thought. An increased number of these cells is found not only within inflamed mucosa (2), but also within apparently healthy mucosa (2). Furthermore, eosinophils were also shown to infiltrate early recurrent lesions in the neo-terminal ileum after surgery $(3,4)$. Eosinophils were also present within myenteric nerves on the section margins of resected ileum and this infiltration was predictive of early endoscopic recurrence at the anastomotic site (5). In addition, we have recently described an increased number of eosinophils in the induced sputum of patients with Crohn disease most of whom had clinically inactive disease (6). All these data highlight the panmucosal infiltration with eosinophils in Crohn disease and suggest that this panmucosal eosinophilia may be constitutive to the disease or at least represent an early phenomenon in the development of mucosal inflammation.

Theoretically, there may be many mechanisms responsible for this eosinophil mucosal infiltration. This might involve an increased life span of eosinophils in the mucosa, an increased production of chemotactic agents by the mucosa, a modification of expression of adhesion molecules in the mucosal blood vessels or finally a modification of the response of blood eosinophils to chemotactic agents. Several eosinophil chemotactic agents have been identified, including lipid mediators, small-molecular-weight peptides, growth factors and chemokines including members of the C-C family and the C-X-C family (7). Some of them including PAF (8), IL-5 (3, 9), 
IL-8 (10), RANTES (11) and Eotaxin (12) have already been shown to be produced in increased amount in the mucosa of the digestive tract in Crohn disease.

The aim of this study was to assess the chemotactic response of peripheral blood eosinophils to these chemokines in quiescent Crohn disease.

\section{Materials and Methods}

\section{Patients and controls}

We studied 15 patients with Crohn disease. The diagnosis of Crohn disease was made by using standard clinical, radiological and endoscopic criteria. There were 11 women and 4 men. Mean age was 35 years (range, 23-57 years). The mean time since diagnosis was 75 months (range, 7-182 months). The disease was located in the small bowel in 5 patients, the colon in 6 and both the colon and small bowel in 4 cases. All the patients had inactive disease at the time of the study (CDAI $(13)<150)$. Three patients had a past history of extra-intestinal manifestation of the disease (peripheral arthritis: 2; erythema nodosum, conjunctivitis and peripheral arthritis: 1). No such symptom was present at the time of the study. Ten patients were treated with 5-aminosalicylic acid (2-4 $\mathrm{g}$ /day), 5 were treated with azathioprine (100-175 mg/ day) and $5 \mathrm{had}$ no treatment. Eight patients were smokers. No patient had a previous history of atopy and none of them had positive skin test for common aeroallergens (house dust mite, grass pollen, tree pollen, weed pollen, cat and dog dander, feathers and moulds). All the patients had a normal blood eosinophil count (mean (range), $1.9 \%(0.3 \%-3.2 \%)$ ) and serum IgE (mean (range), $7.2 \mathrm{KU} / \mathrm{I}(0.5-13.4 \mathrm{KU} / \mathrm{I}))$.

We also studied 15 healthy controls matched for age and sex (11 women and 4 men; mean age, 29 years (22-37 years)). All the controls had normal blood eosinophil count, serum IgE and negative skin prick tests.

Ethics approval was obtained for the study and all the patients and controls gave their informed consent.

\section{Eosinophil chemotaxis}

Eosinophils were purified from the peripheral blood by a negative immunomagnetic technique as previously described (14). Peripheral venous blood (45 ml) was obtained from Crohn disease patients and controls on heparinized tubes $(10 \mathrm{U} / \mathrm{ml})$. Blood was diluted $1 / 2$ with an identical volume of dPBS/FCS $2 \%$ (dPBS (BioWhitaker, Germany): composition, g/l: $\mathrm{KCl}: 0.2 ; \mathrm{NaCl}: 8, \mathrm{Na}_{2} \mathrm{HPO}_{4}: 1.15 ; \mathrm{KH}_{2} \mathrm{PO}_{4}: 0.2$; heat inactivated fetal calf serum (PCS) 2\% (BioWhitaker, Germany); $\mathrm{pH} 7.4$ ). Diluted blood (30 ml) was carefully layered on top of $18 \mathrm{ml}$ isotonic percoll (density, $1.082 \mathrm{~g} / \mathrm{ml}$ ) and centrifuged at $600 \mathrm{~g}$ for 30min at room temperature. To prepare isotonic percoll, $100 \%$ percoll was diluted with Hepes/HBSS (HBSS (BioWhitaker, Germany): composition, g/l: $\mathrm{CaCl}_{2}: 0.185 ; \mathrm{MgCl}_{2}: 0.1 ; \mathrm{MgSO}_{2}: 0.1 ; \mathrm{KCl}: 0.4 ; \mathrm{NaCl}: 8 ; \mathrm{Na}_{2} \mathrm{HPO}_{4}: 0.48 ; \mathrm{KH}_{2} \mathrm{PO}_{4}: 0.06$ $\mathrm{NaHCO}_{3}$ : 0.35; glucose: 1; Hepes (Boehringer, Germany) $4.8 \mathrm{~g} / \mathrm{l} ; \mathrm{pH} 7.4$ ) to a density of 1.082. Following centrifugation, the upper layer containing the polymorphonuclear cells (PMN) was carefully removed and placed into another tube. Red cells were lysed for $15 \mathrm{~min}$ at $4{ }^{\circ} \mathrm{C}$ in a buffer containing, mmol/l: $\mathrm{NH} 4 \mathrm{Cl}: 155 ; \mathrm{KHCO}_{3}$ : 10 and EDTA: 0.1; pH 7.4). To complete the lysis of erythrocytes, the resulting PMN were resuspended in $\mathrm{H}_{2} \mathrm{O}$ at $4{ }^{\circ} \mathrm{C}$ for $30 \mathrm{sec}$, and then washed twice with PBS/FCS $\left(150 \mathrm{~g}\right.$ for $5 \mathrm{~min}$ at $\left.4{ }^{\circ} \mathrm{C}\right)$ and finally resuspended in $500 \mu \mathrm{l} \mathrm{PBS} / F C S$. One hundred $\mu \mathrm{l}$ of anti-CD 16 MACS-microbeads were added and the cells were left at $4{ }^{\circ} \mathrm{C}$ for $30 \mathrm{~min}$ to allow neutrophils to become labelled by the anti-CD 16 antibodies. To separate unlabelled eosinophils from magnetically labelled neutrophils, PMN were layered on top of a MACS-column type C (Miltenyi Biotec Inc., Sunnyvale, CA, USA) which was placed inside a strong magnetic field. Unlabelled eosinophils were eluted with $25 \mathrm{ml}$ PBS/FCS whereas magnetically labelled neutrophils were retained on the column due to a strong magnetic field. This procedure resulted in about $97 \%$ pure eosinophils with neutrophils as contaminating cells. Viability of eosinophils was $>97 \%$ as measured by trypan blue exclusion. The number of eosinophils isolated from $45 \mathrm{ml}$ blood from normal and Crohn disease donors was $0.047 \pm 0.007 \times 10^{6}$ cells and $0.083 \pm 0.025 \times 10^{6}$ cells, respectively $(P=0.24)$.

Eosinophil chemotaxis was assessed by using 48-well microchambers (15). The lower and the upper chambers were separated by a PVP free filter the thickness of which was $8 \mu \mathrm{m}$. The lower chamber was filled with $25 \mu 1$ of a suspension containing the chemotactic agent while $50 \mu \mathrm{l}$ of an eosinophil suspension $\left(1 \times 10^{6}\right.$ cells $\left./ \mathrm{ml}\right)$ was placed in the upper chamber. Both eosinophils and the several chemotactic agents were suspended in the same appropriate buffer (HBSS (BioWhitaker, Germany): composition, g/l: $\mathrm{CaCl}_{2}: 0.185 ; \mathrm{MgCl}_{2}: 0.1 ; \mathrm{MgSO}_{2}: 0.1$; $\mathrm{KCl}: 0.4 ; \mathrm{NaCl}: 8 ; \mathrm{Na}_{2} \mathrm{HPO}_{4}: 0.48 ; \mathrm{KH}_{2} \mathrm{PO}_{4}: 0.06 ; \mathrm{NaHCO}_{3}$ : 0.35; glucose: 1; with Hepes $4.8 \mathrm{~g} / 1, \mathrm{pH}$ 7.4; Ca: 1 ; Mg: 1 ; supplemented with $0.1 \%$ bovine serum albumine (BSA, Behring, Germany)). The chemotactic agents 
tested in the study were IL-5 at 0, 2, $20 \mathrm{ng} / \mathrm{ml}$ (Genzyme, Cambridge, UK), IL-8 at 0, 5, $50 \mathrm{ng} / \mathrm{ml}$ (Genzyme, Cambridge, UK), PAF at $0.1 \mu \mathrm{M}$ (Sigma Chemical Company, St Louis, MO, USA), RANTES at $50 \mathrm{ng} / \mathrm{ml}$ (BioSource, California, USA) and Eotaxin at 0, 5, $50 \mathrm{ng} / \mathrm{ml}$ (PeproTech EC Ltd, London, UK). Chemotaxis chambers were incubated at $37^{\circ} \mathrm{C}$ for $1 \mathrm{~h}$. Filters were removed and non-migrated cells were scraped from the upper side of the filter. The filters were stained (Diff-Quick, Dade Behring Marbourg GmbH, Germany) and the number of migrated eosinophils per 10 high power fields was counted under light microscopy (magnification 60 $\times 10$ ). A positive chemotactic response was defined as the migration of eosinophils through the filter and adherence to the lower side. Each experimental condition was performed in triplicate. Results are given as the absolute number of cells having migrated with or without chemotactic agents or as chemotactic index (CI), which is defined as the ratio of the number of cells migrating through the filter in the presence and absence of chemotactic agents.

\section{Sputum induction and processing}

Sputum was induced after premedication with $400 \mu \mathrm{g}$ inhaled salbutamol by inhalation hypertonic saline $(4.5 \%)$ for up to 5-min periods. The whole collected sputum was processed using DTT (dithiotreitol, Sigma) $7 \mathrm{mM}$ for $30 \mathrm{~min}$ at room temperature and subsequently centrifuged for $10 \mathrm{~min}(400 \mathrm{~g})$ as previously described (16). Total and squamous cell counts were performed on a manual hemocytometer and samples with percentage squamous cell count $>30 \%$ discarded. Cytospins were made from the cellular phase and stained with May-GrünwaldGiemsa. The differential cell count was performed by counting 600 cells (excluding squamous cells).

\section{Statistical analysis}

Data relative to the chemotaxis were expressed as mean $\pm s_{\bar{x}}$. The assessment of the chemotactic effect of the various agents within a group was performed by a paired $t$ test. Comparison of the chemotactic effect between the groups was performed by comparing the chemotactic indexes using an unpaired $t$ test with the Welsh correction.

Cell composition of the sputum was compared between patients and controls by using the Mann-Whitney test and data are expressed as median and range. Correlation between sputum eosinophils and blood eosinophil chemotaxis was assessed by the Spearman correlation test. All values of $P<0.05$ were considered to be significant

\section{Results}

The chemotactic responses of eosinophils induced by the various agents tested are shown in Table I.

Table I. Response of eosinophils to various chemotactic agents. The results correspond to the mean number of migrated eosinophils per 10 high power fields $\left( \pm s_{\bar{x}}\right)$. Intragroup comparisons made using a paired t test

\begin{tabular}{llcc}
\hline & & Controls $(\boldsymbol{n}=\mathbf{1 5})$ & CD patients $(\boldsymbol{n}=\mathbf{1 5})$ \\
\hline PAF & $0 \mathrm{M}$ & $28.21 \pm 3.31$ & $25.77 \pm 3.96$ \\
RANTES & $10^{-7} \mathrm{M}$ & $39.2 \pm 5.77^{* *}$ & $48.67 \pm 4.6^{* *}$ \\
& $0 \mathrm{ng} / \mathrm{ml}$ & $23.36 \pm 2.45$ & $25.85 \pm 3.81$ \\
$\mathrm{IL}-5$ & $50 \mathrm{ng} / \mathrm{ml}$ & $33.07 \pm 4.11^{*}$ & $38.15 \pm 5.58^{* *}$ \\
& $0 \mathrm{ng} / \mathrm{ml}$ & $27.07 \pm 3.41$ & $27.4 \pm 4.34$ \\
& $0.2 \mathrm{ng} / \mathrm{ml}$ & $23.33 \pm 3.36$ & $34.73 \pm 4.45$ \\
& $2 \mathrm{ng} / \mathrm{ml}$ & $34.57 \pm 4.27$ & $38.79 \pm 5.41^{*}$ \\
IL-8 & $20 \mathrm{ng} / \mathrm{ml}$ & $38.73 \pm 8.0$ & $43.53 \pm 5.1 * *$ \\
& $0 \mathrm{ng} / \mathrm{ml}$ & $31.14 \pm 4.03$ & $24.46 \pm 3.12$ \\
& $0.2 \mathrm{ng} / \mathrm{ml}$ & $28.25 \pm 2.66$ & $27.45 \pm 4.03$ \\
& $2 \mathrm{ng} / \mathrm{ml}$ & $39.5 \pm 6.05$ & $36.27 \pm 5.3 * *$ \\
Eotaxin & $20 \mathrm{ng} / \mathrm{ml}$ & $34.0 \pm 3.75$ & $40.0 \pm 6.02^{*}$ \\
& $0 \mathrm{ng} / \mathrm{ml}$ & $31.29 \pm 3.35$ & $25.38 \pm 4.58$ \\
& $0.5 \mathrm{ng} / \mathrm{ml}$ & $25.13 \pm 2.21$ & $26.43 \pm 4.11$ \\
& $5 \mathrm{ng} / \mathrm{ml}$ & $29.38 \pm 5.04$ & $33.43 \pm 5.83^{*}$ \\
$* P<0.05 ; * *$ & $<0.01 . C D=$ Crohn disease. & $44.5 \pm 7.74$ & $56.77 \pm 7.51^{* *}$ \\
\hline
\end{tabular}


The spontaneous migration of eosinophils was similar in patients with Crohn disease and controls $(25.82 \pm 2.51$ and $28.74 \pm 1.95$ eosinophils/10 fields, respectively, $P>0.05)$. In both controls and Crohn disease patients, PAF $(0.1 \mu \mathrm{M})$ and RANTES $(50 \mathrm{ng} / \mathrm{ml})$ caused a significant chemotaxis (Table I). The PAF chemotactic index (CI) was significantly higher in Crohn disease than in controls $(2.09 \pm 0.24$ versus $1.37 \pm 0.14, P=0.02)$ while this was not observed when comparing the RANTES CI between the two groups $(1.54 \pm 0.15$ versus $1.49 \pm 0.16, \mathrm{NS})$ (Table II). As far as IL-5, IL-8 and Eotaxin, mere was no significant chemotactic effect in controls. This contrasts with what we found in Crohn disease patients in whom these cytokines induced a dose-related and significant eosinophil chemotaxis (Table I). Furthermore, for Eotaxin at a concentration of $50 \mathrm{ng} / \mathrm{ml}$ the CI was significantly higher in Crohn than controls (Table II, Fig. 1). Such a significant difference was not observed for a lower concentration of Eotaxin nor for the various concentrations of IL-5 and IL-8 (Table II).

Table II. Eosinophil chemotactic index (CI) for the various chemotactic agents tested in controls and Crohn disease (CD). Intergroup comparisons made using unpaired t test with Welsh correction

\begin{tabular}{lccc}
\hline & & Controls $(\boldsymbol{n}=\mathbf{1 5})$ & CD patients $(\boldsymbol{n}=\mathbf{1 5})$ \\
\hline PAF & $10^{-7} \mathrm{M}$ & $1.37 \pm 0.14$ & $2.09 \pm 0.24^{*}$ \\
RANTES & $50 \mathrm{ng} / \mathrm{ml}$ & $1.49 \pm 0.16$ & $1.54 \pm 0.15$ \\
IL-5 & $0.2 \mathrm{ng} / \mathrm{ml}$ & $1.07 \pm 0.19$ & $1.26 \pm 0.16$ \\
& $2 \mathrm{ng} / \mathrm{ml}$ & $1.44 \pm 0.17$ & $1.58 \pm 0.19$ \\
& $20 \mathrm{ng} / \mathrm{ml}$ & $1.58 \pm 0.36$ & $1.87 \pm 0.30$ \\
IL-8 & $0.2 \mathrm{ng} / \mathrm{ml}$ & $1.17 \pm 0.21$ & $1.26 \pm 0.16$ \\
& $2 \mathrm{ng} / \mathrm{ml}$ & $1.51 \pm 0.24$ & $1.53 \pm 0.10$ \\
& $20 \mathrm{ng} / \mathrm{ml}$ & $1.24 \pm 0.14$ & $1.74 \pm 0.25$ \\
Eotaxin & $0.5 \mathrm{ng} / \mathrm{ml}$ & $0.94 \pm 0.14$ & $1.81 \pm 0.53$ \\
& $5 \mathrm{ng} / \mathrm{ml}$ & $1.05 \pm 0.15$ & $2.27 \pm 0.76$ \\
& $50 \mathrm{ng} / \mathrm{ml}$ & $1.56 \pm 0.28$ & $2.42 \pm 0.18^{*}$ \\
\hline$*<0.05$ & & &
\end{tabular}

Fig. 1. Eosinophil chemotactic index (CI) with Eotaxin in patients with Crohn disease (CD) and controls. CI is defined as the ratio of the number of cells that have migrated through the filter of the Boyden microchamber in the presence and absence of Eotaxin. Values of CI are expressed by the mean $\left( \pm \boldsymbol{s}_{\bar{x}}\right)$ and comparison between Crohn disease and controls was performed by using a t test with Welsh correction.

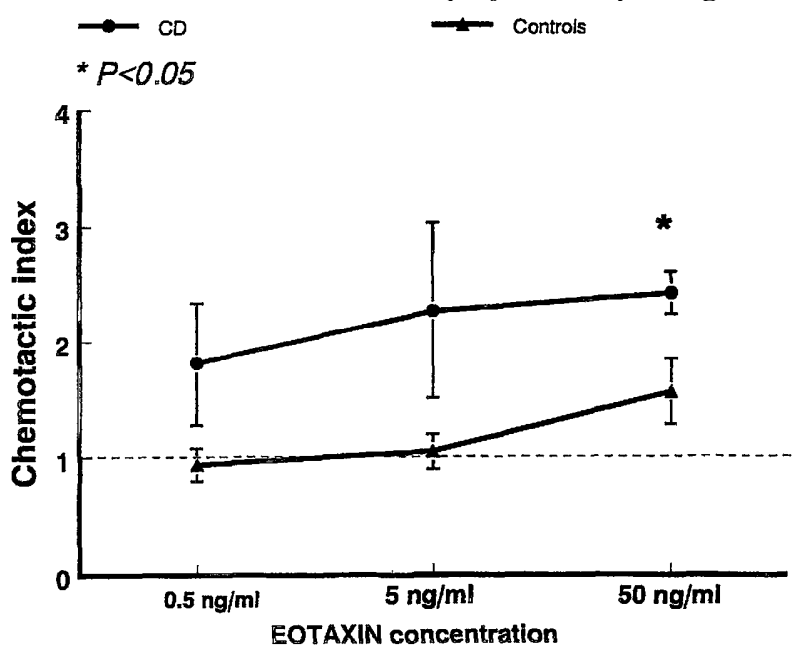

The sputum differential cell counts in Crohn disease patients and controls are given in Table III. The relative number of macrophages was decreased and the relative number of eosinophils was significantly increased in Crohn disease patients $(P<0.001)$. However, we found no significant correlation between sputum eosinophil count and blood eosinophil chemotaxis for the various agents tested in Crohn disease patients. 
Table III. Sputum differential cell counts (\%) in patients with Crohn disease (CD) and controls (median and range). Total numbers of cells were 0.89 and $1.43 \times 10^{6} / \mathrm{g}$ for CD patients and controls, respectively

\begin{tabular}{lcc}
\hline & CD patients $(\boldsymbol{n}=\mathbf{1 2})$ & Controls $(\boldsymbol{n}=\mathbf{1 3})$ \\
\hline Neutrophils & $39.6(6.4-92)$ & $28(6.2-49.7)$ \\
Eosinophils & $1(0-14.5)^{*}$ & $0.2(0-2)$ \\
Macrophages & $31.4(6.6-74.8)^{*}$ & $55.4(43.7-85.6)$ \\
Lymphocytes & $1(0-7.2)$ & $1.7(0-5)$ \\
Epithelial cells & $8(0-70.2)$ & $8(0.7-25)$ \\
\hline$* P<0.001$ & &
\end{tabular}

$* P<0.001$.

\section{Discussion}

Our work shows significant changes in eosinophil chemotaxis in patients with quiescent Crohn disease. We observed a significant chemotactic effect with IL-5, IL-8 and Eotaxin in Crohn disease at concentrations where there was no effect in controls. Furthermore, the chemotaxis assessed by the chemotactic index was significantly increased in Crohn disease for PAF and Eotaxin at concentrations of $10^{-7} \mathrm{M}$ and $50 \mathrm{ng} / \mathrm{ml}$, respectively.

A modification of the profile of response to chemotactic agents as we found in Crohn disease, has been described in several diseases including asthma. In asthma, there is also an increased response to PAF (17) while the response to RANTES has not been shown to be substantially modified (18). Interestingly, an abnormal chemoattraction of eosinophil by IL-8 was also described in asthma. This result was attributed to the priming of eosinophils with some cytokines including IL-5 (19). However, a recent study challenged these data showing that in a highly purified ( $>99.5 \%$ ) population of eosinophils, no chemoattraction was observed even after priming with IL-5 (20). It was suggested that previous results were due to contamination of the eosinophil population with neutrophils and that as little as $5 \%$ of neutrophils in the cell preparation may explain a chemotactic response. However, in that paper, eosinophils from asthma patients were not directly studied. This is in contrast with another recent study on eosinophils of asthma patients in which a purity of $98 \%$ of eosinophils was obtained and a dose-dependent migration was induced with IL-8 (18). Overall this migration profile in asthma was very similar to what we observed in our Crohn disease patients. We further found a significant chemotactic effect of Eotaxin on Crohn disease blood eosinophils from the concentration of $5 \mathrm{ng} / \mathrm{ml}$. Moreover, at $50 \mathrm{ng} / \mathrm{ml}$ the chemotaxis induced by Eotaxin was significantly higher in Crohn disease than in controls. To our knowledge no such data have been clearly published so far for other diseases, including asthma.

Several potential mechanisms may be involved in the abnormal chemotaxis we observed in Crohn disease. Some of them may be shared with other diseases, particularly asthma. For PAF which has already a chemotactic effect on normal eosinophils, an induction of expression of high-affinity binding sites on the plasma membrane may be proposed (17). For IL-5, IL-8 and Eotaxin, aberrant expression and modification of affinity of receptors as well as changes in signal transduction pathways could be involved. As far as IL-8 is concerned, fine regulation may, for example, depend on the type of the receptor expressed, the affinity of the receptor type B (CXCR2) being higher than that of type A (CXCR1) (21). For Eotaxin, no change in its receptor (CCR3) expression has been observed after IL-5 priming, although high levels of expression may constitutively exist in some patients including hypereosinophilic patients (22). These modifications in chemotactic response of eosinophils may thus reflect either a global abnormal activation of blood eosinophils or an increase in the proportion of a particular subpopulation of eosinophils in Crohn disease. All these hypotheses remain to be explored. It must also be kept in mind that cell populations obtained by venepuncture come mainly from the freely circulating pool and may not be completely representative of the whole circulating cells (including the marginated pool). Therefore, the changes in chemotactic response may also reflect changes in the proportion and activation of cells in these freely circulating and marginated pools, respectively, as well as ongoing recruitment from the bone marrow.

The eosinophil chemotaxis is known to be particularly sensitive for cytokine priming $(17,23)$. Relevant blood concentration of several cytokines able to regulate eosinophil functions has been described in active Crohn disease. Proinflammatory or TH1 cytokines, such as TNF $\alpha$, IL-1 $\beta$, IL-6 or IFN- $\gamma$ are increased in active Crohn disease but are close to normal in quiescent Crohn disease (24). However, increased blood concentrations of cytokines known to be particularly influent on eosinophil functions such as GM-CSF, IL-3 or IL-5 have not been described so far. It is worth noting that our patients had quiescent Crohn disease. Although chronic intestinal lesions are dominated by a TH1 type immune response, early recurrent lesions potentially present in still 
clinically quiescent Crohn disease, harbour a TH2 immune profile (25). Therefore, in quiescent Crohn disease, the systemic cytokine environment could be closer to what is observed in asthma. The source and types of priming agents for eosinophils in Crohn disease has still to be clarified. On this point, a recent paper has shown that, beside type 2 lymphocytes, mucosal mast cells are also a significant source of IL-5 in Crohn disease (26). This is particularly relevant when considering the mucosal infiltration with mast cells (27) as well as their activation even in quiescent Crohn disease $(2,28)$. Such an impact of mast cells on mucosal eosinophil migration has already been suggested in asthma (29). Other cells able to influence eosinophil function are neutrophils. These cells are also increased in Crohn disease lesions and also harbour increased capacity of mucosal migration (30). Furthermore, an increased degranulation of these cells has been suggested even in the unaffected intestinal area in Crohn disease patients (31). Interestingly a recent paper showed the potential influence of neutrophil products such as elastase on eosinophil activation and degranulation (32).

In accordance with our previous results (6), we found a significant increase in eosinophil count and a decreased macrophage count in sputum of patients with Crohn disease. The magnitude of sputum eosinophilia was however in the present sample less spectacular than in our previous work. Despite the coupled increase in eosinophil chemotaxis to various chemokines and in mucosal infiltration with eosinophils in Crohn disease, we did not observe a strict correlation between chemotactic response to the various agents tested and sputum eosinophils. This may reflect the complexity of the mechanisms determining mucosal eosinophil infiltration. This is a multifactorial phenomenon in which the magnitude of the chemotactic response of circulating eosinophils to chemokines is only one of the factors involved beside the degree of expression of adhesion molecules, production of chemotactic agents by the mucosa and local survival of eosinophils.

Several studies have already shown an increased production of PAF (8), RANTES (11), IL-5 (3, 9), IL-8 (10) and Eotaxin (12) in the intestinal mucosa of patients with Crohn disease. Combined with the increased chemotactic response toward the agents tested here, this increased production may contribute to the recruitment of mucosal eosinophils. Interestingly, a recent study showed different profiles of production of chemotactic agents in early recurrent lesions of Crohn disease as compared to chronic lesions (Desreumaux, personal communication). The same group had already showed that these early lesions had rather a TH2 immune profile as opposed to the TH1 immune profile of the chronic lesions and that the eosinophils were also relatively more numerous in those early lesions (25). They recently showed significantly higher levels of Eotaxin and RANTES in early compared to chronic lesions. On the opposite, IL-8 was significantly higher in chronic than early lesions. Overall, combining these data with ours, the role of Eotaxin that had the most increased chemotactic effect on eosinophils in our study, seems to be prominent in the recruitment of eosinophils in the mucosa of patients with Crohn disease, particularly in early lesions.

However, important questions remain unsolved and would justify further studies. Among them, the potential variation of eosinophil chemotactic response and mucosal migration according to the activity of the disease and the chronicity of the lesions as well as the possible recruitment of a particular subtype of eosinophils characterized by specific immune or inflammatory function are relevant questions for the understanding of the role of mucosal eosinophilia in Crohn disease. The constitutive or rather secondary nature of this abnormal eosinophil chemotactic response is also an important point to solve. From this point of view, the study of unaffected siblings would represent an elegant approach.

In conclusion, we have shown an abnormal chemotactic response of blood eosinophils to PAF, IL-5, IL-8 and particularly Eotaxin in clinically quiescent Crohn disease. However, the specific impact of this chemotactic response on the magnitude and specificity of eosinophil mucosal recruitment, which is a complex phenomenon, remains to be clarified.

\section{Acknowledgement}

E. Louis is Research Associate at the FNRS of Belgium.

\section{References}

1. Fiocchi C. Inflammatory bowel disease: etiology and pathogenesis. Gastroenterology 1998;115:182-205.

2. Bischoff SC, Wedemeyer J, Herrmann A, Meier PN, Trautwein C, Cetin Y, et al. Quantitative assessment of intestinal eosinophils and mast cells in inflammatory bowel disease. Histopathology 1996;28:1-13.

3. Dubucquoi S, Janin A, Klein O, Desreumaux P, Quandalle P, Cortot A, et al. Activated eosinophils and interleukin 5 expression in early recurrence of Crohn's disease. Gut 1995;37: 242-6. 
4. D'Haens G, Geboes K, Peeters M, Baert F, Penninckx F, Rutgeerts P. Early lesions of recurrent Crohn's disease caused by infusion of intestinal contents in excluded ileum. Gastroenterology 1998;114:262-7.

5. D'Haens G, Colpaert S, Peeters M, Baert F, Penninckx F, Rutgeerts P, et al. The presence and severity of neural inflammation predict severe postoperative recurrence of Crohn's disease. Gastroenterology 1998;114:G3950.

6. Louis E, Louis R, Shute J, Lau L, Franchimont D, Lamproye A, et al. Bronchial eosinophilic infiltration in Crohn's disease in the absence of pulmonary disease. Clin Exp Allergy 1999;29:660-6.

7. Wardlaw AJ, Walsh G, Symon A. Mechanisms of eosinophil and basophil migration. Allergy 1994;49:797-807.

8. Kald B, Olaison G, Sjodahl R, Tagesson C. Novel aspects of Crohn's disease: increased content of platelet activating factor in ileal and colonic mucosa. Digestion 1990;46:199-204.

9. Fromont Hankard G, Brousse N, Cézard JP, Emilie D, Peuchmaur M. In situ interleukin 5 gene expression in pediatric Crohn's disease. J Pediatr Gastroenterol Nutr 1997;24:568-72.

10. Mitsuyama K, Toyonaga A, Sasaki E, Watanabe K, Tateishi H, Nishiyama T, et al. IL-8 as an important chemoattractant for neutrophils in ulcerative colitis and Crohn's disease. Clin Exp Immunol 1994;96:432-6.

11. Berrebi D, Banerjee A, Paris R, Potet F, Aigrin Y, Emilie D, et al. In situ RANTES and interferon- $\gamma$ gene expression in pediatric small bowel Crohn's disease. J Pediatr Gastroenterol Nutr 1997;25:371-6.

12. Garcia-Zepeda E, Rothenberg ME, Ownbey RT, Celestin J, Leder P, Luster AD. Human eotaxin is a specific chemoattractant for eosinophil cells and provides a new mechanism to explain tissue eosinophilia. Nat Med 1996;2:449-56.

13. Best WR, Bektel JM, Singleton JW, Kern F. Development of a Crohn's disease activity index: national cooperative Crohn's disease study. Gastroenterology 1976;70:439-44.

14. Hansel TT, De Vries IJM, Iff T, Rihs S, Wanolzilak M, Betz S, et al. An improved immunomagnetic procedure for the isolation of highly purified human blood eosinophils. J Immunol Methods 1991;145:105-10.

15. Boyden S. The chemotactic effect of mixtures of antibody and antigen on polymorphonuclear leukocytes. J Exp Med 1962;115: 453-66.

16. Louis R, Shute J, Biagi S, Stanciu L, Marrell F, Temor H, et al. Cell infiltration, ICAM-1 expression, and eosinophil chemotactic activity in asthmatic sputum. Am J Respir Crit Care Med 1997;155:466-72.

17. Warringa RAJ, Mengelers HJJ, Kuijper PHM, Raaijmakers JAM, Bruijnzeel PLB, Koenderman L. In vivo priming of platelet-activating factor-induced eosinophil chemotaxis in allergic asthmatic individuals. Blood 1992;79:1836-41.

18. Lampinen M, Rak S, Venge P. The role of interleukin-5, interieukin-8 and RANTES in the chemotactic attraction of eosinophils to the allergic lung. Clin Exp Allergy 1999;29:314-22.

19. Schweizer RC, Welmers BAC, Raaijmakers JAM, Zanen P, Lammers J-WJ, Koenderman L. RANTES- and interleukin-8-induced responses in normal human eosinophils: effects of priming with interleukin-5. Blood 1994;83:3697-704.

20. Petering H, Götze O, Kimmig D, Smolarski R, Kapp A, Eisner J. The biologic role of interleukin-8: functional analysis and expression of CXCR1 and CXCR2 on human eosinophils. Blood 1999;93:694-702.

21. Chuntharapai A, Kim J. Regulation of the expression of IL-8 receptor A/B by IL-8: possible functions of each receptor. J Immunol $1995 ; 155: 2587-94$

22. Heath H, Qin S, Rao P, Wu L, LaRosa G, Kassam N, et al. Chemokine receptor usage by human eosinophils. J Clin Invest 1997;99:17884.

23. Warringa RAJ, Koenderman L, Kok PTM, Kreukniet J, Bruijnzeel PLB. Modulation and induction of eosinophil chemotaxis by granulocyte-macrophage colony-stimulating factor and interleukin-3. Blood 1991;77:2694-700.

24. Louis E, Belaiche J, Van Kemseke C, Franchimont D, De Groote D, Geenen V, et al. A high serum concentration of interleukin-6 is predictive of relapse in quiescent Crohn's disease. Eur J Gastroenterol Hepatol 1997;9:939-44.

25. Desreumaux P, Brandt E, Gambiez L, Emilie D, Geboes K, Klein O, et al. Distinct cytokine patterns in early and chronic ileal lesions of Crohn's disease. Gastroenterology 1997;113: 118-26.

26. Lorentz A, Schwengberg S, Mierke C, Manns MP, Bischoff SC. Human intestinal mast cells produce IL-5 in vitro upon IgE receptor cross-linking and in vivo in the course of intestinal inflammatory disease. Eur J Immunol 1999;29:1496-503.

27. Gelbmann CM, Mestermann S, Gross V, Kollinger M, Schol-merich J, Falk W. Strictures in Crohn's disease are characterized by an accumulation of mast cells colocalised with laminin but not with fibronectin or vitronectin. Gut 1999;45:210-7. 
Published in: Scandinavian Journal of Gastroenterology (2001), vol. 36, pp. 190-195

Status : Postprint (Author's version)

28. Raithel M, Schneider HT, Hahn EG. Effect of substance P on histamine secretion from gut mucosa in inflammatory bowel disease. Scand J Gastroenterol 1999;34:496-503.

29. Bettiol J, Radermecker M, Sele J, Henquet M, Cataldo D, Louis R. Airway mast-cell activation in asthmatics is associated with selective sputum eosinophilia. Allergy 1999;54:1188-93.

30. Brandt E, Muller-Alouf H, Desreumaux P, Woerly G, Colombel JF, Capron M. Circulating growth-regulator oncogene alpha contributes to neutrophil priming and interleukin-8-directed mucosal recruitment into chronic lesions of patients with Crohn's disease. Eur Cytokine Netw 1998;9:647-53.

31. Hällgren R, Colombel JF, Dahl R, Kjell F, Kruse A, Jacobsen NO, et al. Neutrophil and eosinophil involvement of the small bowel in patients with celiac disease and Crohn's disease: studies on the secretion rate and immunohistochemical localization of granulocyte granule constituents. Am J Med 1989;86:56-63.

32. Liu H, Lazarus SC, Caughey GH, Fahy JV. Neutrophil elastase and elastase-rich cystic fibrosis sputum degranulate human eosinophils in vitro. Am J Physiol 1999;276(1 Pt 1):L28-34. 